Monika Mazur-Bubak

Jagiellonian University (Poland)

\title{
A Few Problems with Mouffe's Agonistic Political Theory
}

\begin{abstract}
The main goal of examining a single philosophical theory, connected with social and political disciplines, is not just to identify its incoherence or to restate the theory in a more elegant way. More important in that kind of investigation is to show its possible impact on people's lives and the functioning of communities. Thus, it seems more reasonable to conduct a critical analysis of the possible consequences for a real society than to undertake a simple study of the argument's logical consistency. The main aim of this paper is to introduce doubts about the thesis of Chantal Mouffe presented by her in Agonistics. Thinking the World Politically and Passion and Politics. Main hypothesis is that thinking about the "political" and "politics" with reference to enmity as well as claiming that the source of every political and social activity is antagonism, can provoke an attitude that social and political scenes are battlefields rather than an agora or the space of human interactions. First of all, the author provides the critical analysis and reconstruction of the most important claims connected with the "political", which can have strong negative effects - i.e. brutalization and creating a negative basis for social relation. Then presents a few possible sources of thinking of "political" as a "competition" or rather "enmity". The last part it is the critic of what Mouffe claims about reason why people get involve into politics, based on the psychological experiments and in result of this the author shows the importance of validity the high standards in politics, diplomacy and relation on the social level.
\end{abstract}

Keywords: Agonism, antagonism, Mouffe, Freud, aggression, liberal-democracy, nature of politics

\section{Introduction}

The sense of research into philosophical concepts within political communities is not only expressed in the study of inconsistencies or elegance of a given theory. What appears to be a much more important factor is the influence of a theory on the functioning and existence of those communities. Consequently, it is a rationale for studying potential negative consequences which may (but do not have to) appear in the real life of societies. The main focus of this article are Chantal Mouffe's theses presented in Agonistics. Thinking the World 
Politically (2013). First of all, Carl Schmitt's (2008) concept of the political is subjected to critical analysis. While examining Mouffe's theses, it is first and foremost necessary to reliably separate the ones which may adversely impact the functioning of political communities, from those remaining neutral and potentially helpful in building political institutions increasingly closer to perfection in meeting the needs of these communities. To this end, several of her concept's fundamental assumptions should be tested in terms of possible impact.

Mouffe is regarded as one of key figures in post-Marxism, which emerged in the 1980s. Her most important work was published together with Ernesto Laclau's Hegemony and Socialist Strategy (1985), a seminal publication for the thinkers of the left. At the same time, it expressed - as did her later work - criticism for neoliberalism. On the one hand, this theory is a continuation of concepts of such thinkers as Rose Louxembourg, Eduard Bernstein, George Sorel or Antonio Gramsci; on the other hand, it makes use of arguments based on poststructuralism, on the criticism of the rational subject stemming from Wittgenstein's language games, Gadamer's hermeneutics and Freud's psychoanalysis theory (Mouffe, 2005). The political as formulated by Mouffe is an important voice in the criticism of liberal democracy, primarily due to the recognition of inconsistencies within it. She follows Schmitt in her claims that liberalism is focused on the cosmopolitan vision of humanity, while the focus democracy is the distinction of demos within humanity. Hence the reference is made to Schmitt's division into "us" and "them", which is considered the basis of political relations (Schmitt, 2008). Moreover, the author of Agonistics criticizes the naïve optimism of Rawls' (1999) or Habermas' (2000) positions, which represent the deliberative democracy trend, which assumes the possibility of eliminating conflicts at least at a certain level of debate (Mouffe, 2007). In other words, there should be institutions which eliminate conflicts and allow for the development of rational solutions to problems within the space of political debates. Mouffe indicates, however, that such a situation does not allow for the actual pluralism of positions because some of them cannot be combined with any kind of consensus (2007).

\section{Fundamental Theses at the Basis of the Theory of the Political as Antagonism}

The thinker criticizes and rejects completely the prospect of building collective or political identities if it is not based on the principle of fight for domination between opposing groups. She admits directly that all such designs basically negate or thwart the political as such. At the same time, it should be noted that the author considers one position on defining the political as adequate: the concept by Schmitt, according to which the political is built on the opposition of two positions, while the enemy and the friend are the proper categories for the political. Schmitt's image of politics is thus based on the dualism of positions, which duality is in a sense enforced because it arises not by self-determination, but by imposing the term "them" from which, in a way, "us" is extracted. Of course, Mouffe does not want a direct 
return to Schmitt's concepts - she acknowledges that liberal democracy can be brought out of the impasse only by means of a critical approach and by referring to the arguments of the critics of liberalism (2007).

The criticism of liberal democracy by referring to the arguments of its opponents - first and foremost Schmitt's arguments, is based on three main assumptions:

1. Mouffe assumes that such an identity develops as distinct from "others" (she refers to numerous considerations, for example the thesis of a constitutive outside). "There is no identity that is self-present to itself and not constructed as difference and that any social objectivity is constituted through acts of power. It means that any social objectivity is ultimately political and has to show traces of the exclusion which governs its constitution, what we call its "constitutive outside". As a consequence, all systems of social relations imply to a certain extent to relations of power, since the construction of a social identity is an act of power" (Mouffe, 1993, p. 141). Liberal democracy - as she acknowledges - is focused on the individualistic vision of reality and ignores the fact of group identity development.

2. Such an us-them relationship does not necessarily have to be antagonistic and it only becomes such when we define others as those who take away our identity.

3. She recognizes an irremovable conflict as the nature of politics.

On this basis, auxiliary assumptions are also made:

- in a political system in which there are no legitimate forms of expressing antagonisms, political institutions do not fulfil their task (representation of real views), and only fulfil a façade function;

- in a situation where there are no legal and proper channels for antagonisms, then there is a high probability that the accumulated tensions will lead to an explosion (high ratings of political groups and parties which promote populist, xenophobic or fundamentalism should be considered as such);

- there is no room for consensus in the antagonistic clash of positions, because those systems are hegemonic;

- forced pursuit of consensus leads to apathy in political and social activities.

One of the most important foundations or preliminary assumptions in Mouffe's considerations is indicating an emotive source of engagement in political issues and considering irremovable conflict as the fundament of the nature of the political and therefore collective identities (2005).

\section{Verification of Several Aspects of Mouffe's Politics at the Theoretical Level}

The first of those assumptions concerns the core of her theory which is the criticism of the political proper to the theory of liberal democracy primarily represented by Rawls (1999; $1998 ; 1993)$. This criticism directly refers to the considerations of S. Freud - mainly to the 
concept of psychoanalysis. Apparently, there is a strong conviction that people act (engage in political and social activities) because of passions - especially the passion associated with the fight against someone. Theorists who want to liberate politics from passion and thus to reduce democratic politics to reason and consensus, show their misunderstanding of the dynamics of the political, while ignoring the fact that democratic politics in fact needs human desires and fantasies. What is needed is the development of forms of identification conducive to democratic practice rather than perpetuating the opposition of interests versus feelings or mind versus passions (Mouffe, 2005).

Verification of the assumptions can begin with referring Ralws' concept which is considered a model theory of liberal-democracy. Rawls does not encourage giving up internal and diverse motivations to participate in socio-political discourse. What he indicates as that the most important issue for political liberalism is establishing a level of agreement, while maintaining individuals' deep convictions which in general are contradictory to each other: "How is it possible that there may exist over time a stable and just society of free and equal citizens profoundly divided by reasonable though incompatible religious, philosophical, and moral doctrines?" (Rawls 2005 [1993], xviii). Political liberalism, therefore, involves establishing rules which will create a space for expressing views in a way that will be acceptable to other entities and a language that will allow communication and mutual respect.

Moreover, the second important theme touches upon Freud's Beyond the Pleasure Principle (2014) which discusses several drives which have major impact on human activity - Thanatos and Eros. He defines the impulse called Eros as the instinct of life responsible for all activities aimed at synthesis, including all kinds of creativity. On the other hand, the thinker recognized that the second source of human activity is Thanatos - the drive for death. It is often sublimated to other entities and objects, which manifests itself in negation, aggression and the desire to destroy all order. Mouffe notes that in the contemporary liberal-democracy, the human rationality or caring for one's own interest are considered the main reasons for engaging in any activity $(2000, \mathrm{p}$. 146). The thinker acknowledges that the dynamics of politics is subject to other motives - i.e. human passions, and above all the desire and the need to compete. She indicates that allowing such motivation may breathe new life into politics, make it reflect real views and attitudes ${ }^{1}$. The first doubt that arises when those two theories are juxtaposed concerns accepting only the Thanatos-related activity aspects as the basis for motivation in socio-political activity - that is, negating the order, negating the existence of others (antagonism) while ignoring the aspects associated with Eros, which would account for synthesizing different views and positions ${ }^{2}$. It can be pointed out that

1 By limiting themselves to calls for reason, moderation and consensus, many democratic parties are showing their lack of understanding of the functioning of political logic. They do not understand the need to counter their adversaries by mobilizing affects and passions in a progressive direction (Mouffe, 2000, p. 148).

2 This position is represented by M. Nussbaum in Political emotions, in which she convincingly argues 
hegemony, which Mouffe considers to be characteristic of political relations, also emphasizes the aspect of negating others - hence, it is connected with Thanatos. One can certainly agree with the statement that negative emotions have a stronger impact on the human imagination and therefore constitute a stronger motivation to act. For obvious reasons, all populist movements are based on this regularity (the fact that they emerge, according to Mouffe, is a manifestation of inappropriate management of anatagonism-triggered action energy).

\section{Verifying the Basics of Mouffe's Political at the Experimental Level}

A simplified version of the hydraulic model of aggression is the aspect Freud's concepts which is fundamental for Mouffe's vision of the political. In this model, the accumulated aggression which does not find an outlet causes tension which can only be released in an explosion. Society, on the other hand, is supposed to direct the instinct of aggression by creating paths of its sublimation (Aronson, Wilson, Akert, 2013). To verify the hydraulic theory of aggression, according to which agonistic politics should release accumulated aggression and adequately (i.e. within set limits) direct its action, it is worth to confront it with the results of several experiments in the field of social psychology, among others: the fury room, anger room or destruction room ${ }^{3}$. This experiment resulted directly from the assumptions of hydraulic theory because it was accepted that a human being has a reservoir of aggression which requires the discharge of "rebound". Lack of aggression release (catharsis) is supposed to lead to internal diseases and ultimately to the outbreak of uncontrolled aggression. In line with this theory "fury rooms" were established in which the reservoir of aggression could be unloaded in a socially harmless way (by demolishing especially prepared rooms). This experiment was supposed to evoke relaxation in the respondents and, eventually, led to a decrease of brutal and aggressive activities in people using the "fury rooms". However, the effects turned out to be opposite: while the rooms did produce short-term relaxation and the effects similar those of intense physical exercise, in the long term they ultimately led to reinforcing the path of aggressive and dysfunctional reactions to psychologically difficult situations. In other words, the release of aggression led to even greater aggression (by reinforcing the attitude based on reacting in this way and extending it to other situations).

Moreover, studies (Bushman, Baumeister, Stack, 1999) indicate that people who were initially informed about the effectiveness of the hydraulic model of aggression are inclined to show more aggressive attitudes and after a single "release" of aggression show significantly increased aggression levels. In other words, the concept of catharsis in conjunction with

that the basic value in a just society is to recognize what we share - that is, recognize that each person is a goal and not a means, the idea of equality of all people, or the idea of equal dignity of every human being. In opposition to Mouffe, she does not recognize that appealing to differences, fight or disputes over these differences defines political relations.

${ }^{3}$ See www.furyroom.fr, www.angerroom.com, www.destructionroom.net. 
adequate persuasion becomes not only a self-fulfilling prophecy but even a dangerous counterfeit.

Another experiment concerned the impact of sport on reducing the level of aggression as a socially acceptable form of competition. Arthur Patterson (1974), refutes the catharsis theory according to which the discharge of tension (aggression) in sports games leads to the reduction of aggression, as he in fact proves the reverse dependence - after sports competitions, the readiness to aggressive behavior increases. Moreover, watching sports competitions without active participation in them leads to increased aggression (Russel, 1983). Direct expression of negative feelings against someone who is the source of aggression was thought to be another potential way to relieve aggression. As it became apparent after experiments performed by Geena and Quanti (1977), a single instance of aggressive behavior in fact increases the likelihood of subsequent similar reactions consequently reinforcing such behavior patterns and leads to the depreciation of the injured (which in turn results from experiencing cognitive dissonance of the self as a just or noble person, and at the same time lowering the value of the injured person). The information gathered in the studies does not provide arguments substantiating the catharsis model: while it seems initially sound, the experience of release involves a temporary feeling of relaxation, which is not to identical to eliminating antagonism or aggression, as it also depends on attitudes or approaches represented by various individuals rather than having purely emotional content (Aronson et al., 2013, pp. 350-351). What is also noteworthy, once aggression is expressed, resistance to aggressive actions is also weakened, giving space for subsequent actions of similar form (Aronson, 2013, pp. 350-351). A negative verification of the catharsis concept leads to possible problematic consequences of applying this concept to understand the political.

The attempt to implement the concept of Freud's psychoanalysis on the level of political and international relations was quite clearly verified by the philosopher himself. After the end of the First World War, he was asked to participate in a project of exchanging views by elected intellectuals aimed at reducing wars. He was invited to this project by Einstein. The correspondence between the two thinkers shows that before World War I, Freud believed that the cultural identity of highly developed countries would be a barrier preventing the outbreak of war. However, after the outbreak, he saw the dissonance between the humanistic development of civilization and the extreme methods of combat and the cruelty of military action. In his view, in wartime moral norms imposed by culture on societies collapse, what ensues is regression to earlier stages of mental life, thus egoism and aggression become prominent (Einstein, Freud, 1932). It can be vividly depicted in this way: the vice of culture ceases to oppress and extreme behaviors awaken in people. Freud's observations of increased brutality when cultural principles are suspended in nations that consider themselves to be civilized (in comparison to other nations) is consistent with the points made by Aronson, Wilson and Akert (2013). They note that the frustration experienced by such civilized societies in crisis situations transforms into aggression in specific circumstances. One such circumstance is the conviction of (authoritatively) having an exceptional identity entitling 
to a privileged position, an identity which societies possess as those of a higher degree of civilization. In such a process relative deprivation occurs, in which an individual or a group believes that it has less than it deserves, or less than others with the same status have (Frank, 1987; Levi, 1985).

The second axiom accepted by Mouffe that is associated with the former one is recognition of the difference between "us" and "them" as the basis of group identity. This aspect was directly borrowed from Schmitt. Therefore, group identity is determined through indicating a group and, subsequently, negating it by a newly formed group.

This time, to verify the consequences of this assumption, one can refer to a rather controversial experiment called Robbers Cave (Sherif, Harvey, White, Hood, Sherif, 1954/1961). It took place in 1954 in the United States in the Robbers Cave State Park in Oklahoma, where two independent camps were created for twelve-year-old boys who had not known each other. During the first week each group created their own distinctive signs and codes of conduct. In the second week there was a stage of arranged competition. The groups learned about each other and were encouraged to compete. The experiment quickly got out of control. The rivalry took no longer an arbitrary but direct form. Each group began to recognize their members as better while heavily discriminating the members of the other group. The competition developed such an aggressive form that both groups had to be physically separated. The crisis was resolved only by chance, because both groups were forced to cooperate during a sudden downpour to prevent flood and destruction of the entire camp. After the experience of cooperation, the level of aggression declined, the demonization of the members of the second group ceased, and mutual discrimination almost completely resolved. Both groups re-established mutual respect towards "rivals", thanks to which they could return in one bus.

What does this situation teach us in the context of Mouffe's considerations? First of all, it is a simple instruction on social engineering, which indicates the circumstances and ways of building social groups that will be hostile towards each other. It is based on defining (or even arbitrarily forming) two groups, which are assigned the task of competing not only for the resources necessary for survival but also for symbols. Dualism in this case becomes dangerous, because even small suggestions about starting a competition can lead to a strong antipathy, which quickly takes the form of aggression. This is related to facilitating the dehumanization of the second group by focusing on the differences rather than similarities between the groups. In the counterpoint, another study (Feshbach and Fesbach, 1969) should be mentioned as it points to a relationship between learning empathy and a stronger emphasis on cooperation (i.e. levelling dehumanizing attitudes) and low level of aggression, even in the case of strong frustration.

Moreover, the Robbers Cave experiment shows that the construction of identity, based on antagonism even at the stage of an already formed community may lead to mutual hatred, discrimination and hostility. Can we then assume that this is the nature of politics? Certainly, it is impossible to ascertain (although some researchers do) that antagonism is the nature 
of political relations. Instead, it is possible to indicate with a high degree of probability what circumstances may potentially lead to extreme forms of expressing antagonisms. Such circumstances include dual or bipolar systems of socio-political relations. Lack of a moderate position leads to a false impression that one group's vision of social reality is predestined to be ultimate, proper or true. The necessity to occupy one of the positions within the framework of duality can and often does lead to radicalization of views and a symbolic withdrawal of the right to have and express other views.

\section{Agonist Policy - Destruction or Release?}

It would seem that the establishment of legal pathways for expressing hostility or opposition is not only a proper way but also a necessary one, however, as indicated by the abovementioned research, the institutionalization of hostility seems to in fact encourage more hostility. The problem of agonistic thinking about politics is omitting the purpose of agon, i.e. the clash. There is no reference to shared values or action as agonistics is a clash project which aims to overcome the opponent. Such an action stands in opposition to the theoretical foundations of contemporary civil societies, in which, according to Kant, the goal of action and the fight itself is the continuity of a community rather than annihilation or defeat of the opponent.

Moreover, Mouffe goes a step further, because by recognizing the antagonistic dimension of politics, she reinforced the view of community as mutually antagonist groups. The concept of reformulating antagonism into agonist politics seems to be erroneous in that it recognizes antagonism as a foundation which should be levelled. Agonism ${ }^{4}$ is understood literally as an accelerating or releasing stimulus, hence the policy of agonism is supposed to lead to the release of conflicts, hence their aggravation.

It also seems that the theory of agonistic politics can build very strong antisocial attitudes based on the belief that the community world is built of conflicts - its defining aspect. Consequently, an air of general consent is created for activities which are socially dysfunctional (asocial) because contemporary liberal-democratic societies operate based on social contracts which even etymologically involve bringing individuals together. On the other hand, antagonistic politics stands in clear contradiction to such a stance, because its task consists in separating, determining the irreconcilable differences, hence it can be assumed that it is essentially anti-social. At a certain point, that air becomes an important and partly covert premise that sets an expected course of action - thus changing into Heidegger's self. Referring to the studies of Berkowitz (1981) and LaPage (1967), it should

${ }^{4}$ Agon - translated both as a conflict between a protagonist and an antagonist, and through the context of ancient Greece as a clash in various fields for a reward. To some extent, the relationship between agon and agony can also be indicated - slow death, effort, fear, and momentum. 
be mentioned that the mere presence of a stimulus that triggers aggression may lead to an increase in the likelihood of aggressive behavior - the participants of the study acted aggressively more frequently when there was an object symbolizing aggression (firearms) in the room. In this context, it is necessary to consider whether that air in which competition (which cannot be clearly separated from fight) is the model rather than cooperation is perhaps the triggering stimulus.

In addition, it can be noticed that the methods of managing conflicts and stagnation in politics (caused by the impossibility of legal explication of conflicts) boil down to the paths verified by the aforementioned research. So, one asks how can aggression acts be reduced at the social level, since both the attempts to suppress and to discharge it can have negative consequences? One strategy that yields satisfactory results is learning to express anger and criticism and to negotiate. Positive conclusions can be drawn from a study conducted by Davitz (1952) who found lower levels of frustration transformed into aggression in a group of children who had previously been taught the principles of cooperation. Those children in fact reacted more rationally and less aggressively even if frustrated than the children who were awarded for competitive approach (Aronson et al., 2013, p. 354).

\section{Implications from Research on Aggression for the Concept of the Political}

The Mouffe project points to a fundamental problem in representative democracy regarding participation in the political and social areas, but it seems that the two axioms presented above are in opposition to the very foundations of contemporary civil societies. It appears that Mouffe wrongly accuses liberal democracy of wanting to overcome the distinction of us versus them, because according to Rawls' (1993), Sen (2009) or even Nussbaum (2004), contemporary concepts of social justice aim to include as many viewpoints as possible in the discourse rather than to eliminate differences, which is what Arendt (2005) would also like, thanks to which empathic attitudes are built. The concept of the law of peoples (Rawls, 1993), impartial spectator - open impartiality by Sen (2009), or the capability theory by Nussbaum (2004) involve abolishing the hostile attitude and establishing the us-you viewpoint instead of us-them. What is extremely important, Robber's Cave experiment, even if controversial and probably impossible to repeat for at least ethical reasons, is immensely revealing in the context of contemporary international relations, because it answers the question: how to merge deeply divided and antagonized groups into one community? Although one should take into account the limitations resulting from specific circumstances and the specificity of the study group, what is noteworthy is the proposal to build a community based on the recognition of a common, important task that requires cooperation, a task which does not involve uniting towards the common enemy (because - again - it would mean the return to an unstable community identity based on negation and having cooperation under competition) but towards a common positive formulation. 
It is worth to ask whether the institutionalization (or rather the legalization) of certain forms of conflicts in the internal policy space is actually reasonable and whether it is an expression of a realistic approach which mainly recognizes the irremovability of conflicts. At this point, it is possible to make an analogy to the concept of just wars within certain limits. Such institutionalization favors managing conflicts within generally accepted principles and becomes an important reference point (although there is no single tribunal here) - the concept of just war is a generally recognized signpost which at least in theory is supposed to reduce abuse. The same applies to internal politics - applying some institutional framework to conflicts results in a kind of "civilization". As Mouffe writes, both sides agree to compete, and when one side wins, the other must accept it. This is more or less the difference between the rival and the enemy. When one of the parties wins, it does not seek to annihilate the rival. As for the enemy in combat, we are dealing here with the direct goal of his annihilation. To this point, the Mouffe project seems to be just such a concept of "ennobling" or "civilizing" internal political games. On the other hand, we are dealing here with the second - a more important thought shift that Mouffe makes following Schmitt's reflections, which involves recognizing conflict as the basis of political relations. Here, too, we can make an analogy to the concept of just war. The claim that the essence of international politics lies in conducting wars should be regarded as highly dangerous. It potentially leads to a situation in which (as H. Arendt wrote) all war activities are deemed both legitimate and justified (for instance, such adverse consequences are implied if Hegel's ideas are followed). Moreover, within international relations, individual entities begin to cooperate in the framework of competition - in other words, the fundamental goal is not actual cooperation or establishing a just relationship but quiet stalking and mutual distrust under the mask of diplomatic correctness.

Of course, to some extent, international relations function in this way - however, as evidenced by the experience of the Cold War, such a state is neither desirable, nor does it guarantee a reasonable level of security (Brzeziński, 2014). Similarly, when a conflict is established as a basis, content or definition in internal relations, similar mutations or even degeneration ensues. The assumption that conflict and various dualisms constitute the basis of political relations consequently results in homogenization and thus oversimplification of approaches, and tensions. Referring only to two entities on the opposite ends of the entire spectrum of positions, means ignoring the vast range in between. In other words, the voice of most groups or entities is ignored, as it is not radical enough (by the standards of such politics). In such a situation, again, the established principles of mutual functioning can be commonly recognized as a demoralizing situation called cooperation within competition. 


\section{Conclusions}

Antagonisms persist in every community but it is worth asking whether they should in fact define the whole relationship. It should be noted that such a manner of defining the political is against the foundations of modern society and against the concept of social contract, within which we should concentrate on the goal of staying within in a community while striving for justice and perfection - contractually drawn together and towards one another. On the other hand, antagonisms express the opposite aspiration: separating and extracting. Social contract, however, does not imply the unification of positions. It involves recognizing the whole spectrum of possible positions, rather than focusing on the alternative. It can therefore be pointed out that, as in Kant's vision of moving towards eternal peace, we must establish preliminaries which have to be followed until the eternal peace (1992). Thus, it seems sensible to establish of legal boundaries or to institutionalize antagonisms within internal relations politics, while it should be remembered that institutions of this type cannot be treated as the main task or the goal of a community.

Designing the pathways for channeling antagonisms should not be considered as the main task within political communities - such an approach should be considered erroneous and even harmful. As indicated by Davitz's (1952) research, contrary to cooperation and empathy training, rewarding competitive attitudes reinforces aggressive behavior. Of course, it should be pointed out that legal ways of expressing possibly antagonistic views are important if not necessary in civil society. However, the sense of building institutions and ways of expressing views is not competition, but to building generally acceptable norms of coexistence. In other words, the center of gravity is shifted from the "enemy" category to the "opponent" category, although it may ostensibly be undermined as an illusory attempt to civilize the conflicting nature of political relations, because it develops the anti-social direction of the Freudian hydraulic model of aggression and the catharsis mechanism which have largely been refuted social psychology $y^{5}$. The above-mentioned studies in the field of social psychology point to numerous dangers related to the adoption of the agonistic concept of the political. The mechanism of the self-fulfilling prophecy should be considered as critical as the emphasis on antagonisms in society likely leads to the polarization of positions and differences between entire social groups and the spread of a belief that the aim of functioning in society is the fight against the opponent rather than building a community.

${ }^{5}$ Or - they been shown to have a decidedly negative impact on the functioning of human communities. 


\section{References}

Arendt, H. (2005). The Promise of Politics, New York: Schocken Books.

Aronson, E., Wilson, T.D., \& Akert, R.M. (2013). Social psychology: The heart and the mind, Boston, Columbus, Indianapolis. New York, NY, US: Pearson.

Berkowitz, L., LePage, A. (1967). Weapons as aggression eliciting stimuli, Journal of Personality and Social Psychology, 7, pp. 202-207.

Berkowitz, L. (1981). How guns control us, Psychology Today, pp. 11-12.

Brzeziński, Z. (2014). Agonia komunizmu, Kraków: Instytut Literacki Kultura - Instytut Książki.

Bushman, B., Baumeister, R., Stack, A. (1999). Catharsis, Aggression and Persuasive Influence: Self-Fulfilling or Self-Defeating Prophecies?, Journal of Personality and Social Psychology, 76(3), pp. 367-376.

Davitz, J. (1952). The effects of previous training on postfrustration behavior, Journal of Abnormal and Social Psychology, 47, pp. 309-315.

Einstein-Freud Correspondence (1931-1932), Retrieved from: http://www.public.asu.edu/ jmlynch/273/ documents/FreudEinstein.pdf.

Frank, J.D. (1978). Psychotherapy and the human predicament. A psychosocial approach, New York: Schocken Books.

Freud, S., \& Hubback, C.J.M. (1922). Beyond the pleasure principle. London: The International psychoanalytical Press.

Geen, R., Quanty, M. (1977). The catharsis of aggression: An evaluation of an hypothesis, in: L.Berkowitz (red.), Advances in experimental social psychology (vol. 10, pp.1-36), New York: Academic Press.

Golden, B. Should You Visit an Anger Room? What to consider before you do, Retrieved from: https:// www.psychologytoday.com/us/blog/overcoming-destructive-anger/201705/should-you-visit-angerroom.

Habermas, J. (2000). The Inclusion of the Other, Cambridge, Massachusetts: The MIT Press.

Laclau, E., Mouffe, Ch. (1985). Hegemony and Socialist Strategy. Towards a Radical Democratic Politics, London: Verso.

Levi, P. (1986). Survival in Auschwitz; and The Reawakening. Two memoirs. New York: Summit Books. Mouffe, Ch. (1993). The Return on the Political, New York: Verso.

Mouffe, Ch. (2000). Politics and Passions: The Stakes of Democracy. Ethical Perspectives, vol. 7, No. 2-3, p. 146.

Mouffe, Ch. (2000). The Democratic Paradox, New York: Verso.

Mouffe, Ch. (2005). On the Political, London, New York, Routledge.

Mouffe, Ch. (2013). Agonistics. Thinking the World Politically, London, New York: Verso.

Nussbaum, M. (2004). Beyond the Social Contract: Capabilities and Global Justice, Oxford Development Studies, vol. 32, No. 1.

Patterson, A. (1974). Hostility Catharsis: A Naturalistic Quasi-Experiment, Personality and Social Psychology Bullerin, pp. 195-197.

Rawls, J. (1999). Theory of Justice, Cambridge, Massachusetts: Harvard University Press.

Rawls, J. (1993). The law of Peoples, Chicago: University of Chicago Press.

Rawls, J. 2005 (1993). Political liberalism. New York: Columbia University Press.

Russell, G.W. (1983). Psychological issues in sports aggression. In J.H. Goldstein (ed.), Sports violence, New York: Springer-Verlag.

Sen, A. (2009). Idea of Justice, Cambridge: The Belknap Press of Harvard University Press Cambridge.

Schmitt, C. (2008). Political Theology. Cambridge: Polit Press. 